\title{
Hypothyroid pseudoacromegaly
}

\section{S D L P Subasinghe ${ }^{1}$, W S T Swarnasri ${ }^{2}$, G A Ratnatilake ${ }^{3}$, N P Somasundaram ${ }^{4}$}

Sri Lanka Journal of Diabetes, Endocrinology and Metabolism 2014; 4: 59

A 70 year old male presented with 2 months history of headache with impaired peripheral vision and 6 months history of progressive enlargement of face, hands and feet together with weight gain, constipation and lethargy. He had acromegaloid features (Figure1) and constricted temporal visual fields. Increased heel pad thickness compatible with acromegaly was noted on Xray. He was found to have homogenous enlargement of the pituitary gland suggestive of a macroadenoma on Magnetic Resonance Imaging (MRI) of brain. Endocrine studies showed TSH $>75 \mu \mathrm{IU} / \mathrm{ml}$ (ref. 0.4-4); Free $\mathrm{T}_{4} 0.36$ ng/dL (ref. 0.89-1.76). A 75g oral glucose tolerance test showed normal suppression of GH level. The constricted temporal visual fields were explained by glaucoma. The patient was started on levothyroxine $100 \mu \mathrm{g}$ daily and his clinical condition, biochemical parameters as well as the secondary pituitary hyperplasia is currently responding well to treatment (Figure 2A and 2B).

The elevated thyrotropin-releasing hormone (TRH) level due to the absence of negative feedback seen in primary hypothyroidism, leads to thyrotroph hyperplasia causing pituitary enlargement, which is a known but rare occurrence (1). Since MRI alone is unable to reliably differentiate between a thyroid stimulating hormone (TSH)-secreting pituitary adenoma and hypothyroidisminduced pituitary hyperplasia dynamic endocrine tests such as blunted TRH stimulation test, elevated alpha subunit concentration and elevated alpha subunit concentration/TSH ratios (2) as well as repeat pituitary MRI after a brief thyroxine trial are used to provide confirmation in similar cases (3). Pituitary hyperplasia usually regresses following adequate hormone replacement over a period of a few months (1). This case illustrates the importance of determining thyroid function tests during the investigation of pituitary masses (4).

\section{References}

1. Jeoung SK, Min SK, Sun JK, Gyung HC, Pyoung HH, Dae-YL. Pituitary hyperplasia secondary to hypothyroidism caused by Hashimoto's thyroiditis in a female adolescent. J Korean Soc Pediatr Endocrinol 2011; 16: 185-8.

2. Joshi AS, Woolf PD. Pituitary hyperplasia secondary to primary hypothyroidism: a case report and review of the literature. Pituitary 2005; 8(2): 99-103.

3. Sarlis NJ, Brucker DF, Doppman JL, Skarulis MC. MRIdemonstrable regression of a pituitary mass in a case of primary hypothyroidism after a week of acute thyroid hormone therapy. J Clin Endocrinol Metab 1997; 82(3): 808-11.

4. Betônico CC, Rodrigues R, Mendonça SC,Jorge PT. Primary hypothyroidism mimicking pituitary macroadenoma. Arq Bras Endocrinol Metabol 2004; 48(3): 423-6.

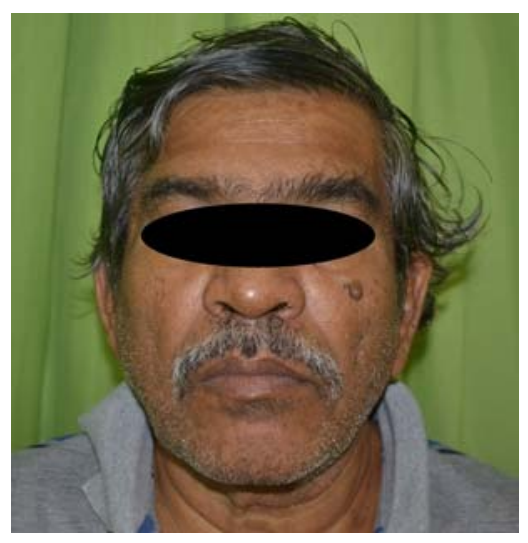

Figure 1. Pretreatment patient - coarse facial features with large nose.
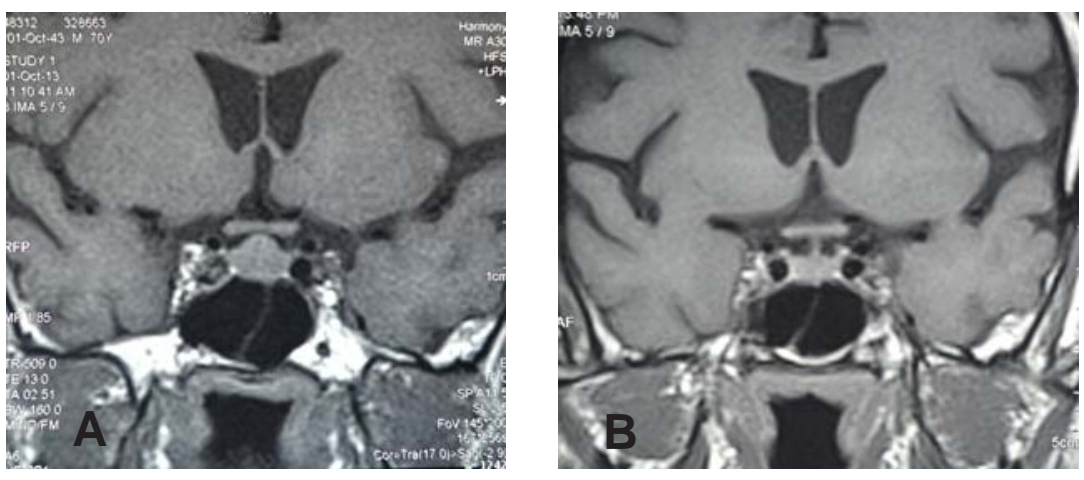

Figure 2. T1 weighted Magnetic Resonance Imaging of pituitary with gadolinium enhancement - coronal section: Pretreatment homogenous enlargement of the pituitary gland extending into suprasellar region without chiasmatic compression (A) and post treatment image with reduced size and bulkiness of the gland (B).

${ }^{1}$ Registrar, General Medicine, ${ }^{2}$ Senior Registrar in Endocrinology, ${ }^{3}$ Consultant Physician, ${ }^{4}$ Consultant Endocrinologist, National Hospital of Sri Lanka. 